\title{
Inequalities by educational level in response to combination antiretroviral treatment and survival in HIV-positive men and women in Europe (1996-2013): a collaborative cohort study
}

\author{
Del Amo, Julia
}

\begin{abstract}
BACKGROUND Socioeconomic inequality challenges population-level implementation of health interventions. We investigated differences by educational level in clinical, virological and immunological responses to combined Antiretroviral Treatment (cART) in HIV-positive men and women in COHERE, a European collaboration. METHODS Data were pooled from 15 cohorts in eight countries of patients initiating cART in 1996-2013 with data on educational level categorized in UNESCO/ISCED classifications. Kaplan-Meier curves, Cox and piecewise linear mixed models were used. RESULTS Of 24,069 HIV-positive patients, $9 \%$ had not completed primary education, $32 \%$ had completed primary, $44 \%$ secondary, and 15\% tertiary education. Overall, $21 \%$ were women, who were over-represented in lower educational strata. During 132,507 person-years of follow-up, 1,081 individuals died; cumulative mortality decreased with higher educational level $(\mathrm{p}<0.001)$. Over 122,765 person-years, new AIDS events or death occurred in 2,598 individuals; differences by education were more marked than for death alone ( $\mathrm{p}$ $<0.001)$. Virological response was achieved by $67 \%$ of patients without completed basic education, $85 \%$ with completed primary education, $82 \%$ with secondary, and $87 \%$ with tertiary $(\mathrm{p}<0.001)$. Patients with higher education had higher CD4-count at cART initiation and at each time after cART but rate of CD4-count recovery did not differ. Differences in mortality and clinical responses were similar for men and women and were not entirely explained by delayed HIV diagnosis and late cART initiation. CONCLUSIONS HIV-positive patients with lower educational level had worse responses to cART and survival in European countries with universal healthcare. To maximize the population impact of cART, Europe needs to decrease the socioeconomic divide.
\end{abstract}

DOI: https://doi.org/10.1097/QAD.0000000000001270

Posted at the Zurich Open Repository and Archive, University of Zurich ZORA URL: https://doi.org/10.5167/uzh-126827

Journal Article

Accepted Version

Originally published at:

Del Amo, Julia (2017). Inequalities by educational level in response to combination antiretroviral treatment and survival in HIV-positive men and women in Europe (1996-2013): a collaborative cohort study. AIDS, 31(2):253-262.

DOI: https://doi.org/10.1097/QAD.0000000000001270 
AIDS

DOI: 10.1097/QAD.0000000000001270

Inequalities by educational level in response to combination antiretroviral treatment and survival in HIV-positive men and women in Europe (1996-2013): a collaborative cohort study

Short title: Educational level and response to ART

Authors: The Socio-economic Inequalities and HIV Working Group for Collaboration of Observational HIV Epidemiological Research in Europe (COHERE) in EuroCoord

\section{Corresponding author:}

Julia del Amo,

National Center of Epidemiology, Instituto de Salud Carlos III,

C/ Sinesio Delgado 628029 Madrid, Spain.

e-mail: jdamo@isciii.es

Tel +34918222142

Abstract word count: 250

Word count: 2872 


\begin{abstract}
Background: Socioeconomic inequality challenges population-level implementation of health interventions. We investigated differences by educational level in clinical, virological and immunological responses to combined Antiretroviral Treatment (cART) in HIV-positive men and women in COHERE, a European collaboration.
\end{abstract}

Methods: Data were pooled from 15 cohorts in eight countries of patients initiating cART in 1996-2013 with data on educational level categorized in UNESCO/ISCED classifications. Kaplan-Meier curves, Cox and piecewise linear mixed models were used.

Results: Of 24,069 HIV-positive patients, 9\% had not completed primary education, $32 \%$ had completed primary, $44 \%$ secondary, and $15 \%$ tertiary education. Overall, $21 \%$ were women, who were over-represented in lower educational strata. During 132,507 person-years of follow-up, 1,081 individuals died; cumulative mortality decreased with higher educational level ( $\mathrm{p}<0.001)$. Over 122,765 person-years, new AIDS events or death occurred in 2,598 individuals; differences by education were more marked than for death alone $(\mathrm{p}<0.001)$. Virological response was achieved by $67 \%$ of patients without completed basic education, $85 \%$ with completed primary education, $82 \%$ with secondary, and $87 \%$ with tertiary $(\mathrm{p}<0.001)$. Patients with higher education had higher CD4-count at cART initiation and at each time after cART but rate of CD4-count recovery did not differ. Differences in mortality and clinical responses were similar for men and women and were not entirely explained by delayed HIV diagnosis and late cART initiation.

Copyright @ 2016 Wolters Kluwer Health, Inc. Unauthorized reproduction of this article is prohibited. 
Conclusions: HIV-positive patients with lower educational level had worse responses to cART and survival in European countries with universal healthcare. To maximize the population impact of cART, Europe needs to decrease the socioeconomic divide.

Keywords: HIV; Mortality; Socioeconomic Factors; Inequality; Cohort Studies 


\section{INTRODUCTION}

Even in settings with universal healthcare access, socioeconomic inequality poses a challenge for implementing healthcare interventions at the population level.

Socioeconomic gradients in morbidity and mortality in men and women are well described in the general population (1-3). In HIV-positive persons, socioeconomic inequalities have been associated with poorer short-term immunological and virological response to combined Antiretroviral Treatment (cART) as well as worse clinical outcomes (4-15).

A large collaboration of HIV cohort studies, the Collaboration of Observational HIV Epidemiological Research in Europe (COHERE), has recently reported inequalities by educational level; a proxy for socioeconomic status, in HIV testing rates and cART initiation in European countries. In these countries with universal access to health care, the study highlighted gender differences (15). Individuals with lower educational level, particularly men, were more likely to present late, with advanced HIV disease, and subsequently were more likely to initiate cART at later stages (15). In cohort studies in France, educational level, employment status, and other socioeconomic variables were associated with mortality (5-6). Educational level predicts all-cause mortality in HIVpositive persons in countries with and without universal health care systems (7-11), although no clear association was evident in Switzerland (12-13).

Few of these studies compared the effects of socioeconomic variables for men and women separately. Indeed, since socioeconomic position may be a poorer predictor of health outcomes in women than in men (16), and the number of women in HIV cohort studies is often lower, potential gender differences are often overlooked. In this study, we build on our previous findings (15) and hypothesize that inequalities by educational 
level persist among patients after treatment initiation, and that impaired response to cART also varies by gender. Our objectives were thus to investigate differences by educational level in virological and immunological response to cART, as well as incidence of all-cause mortality and new AIDS-defining events in HIV-positive men and women in COHERE data from 1996 to 2013.

\section{METHODS}

\section{Study design, setting and participants}

COHERE (www.cohere.org) is a collaboration of 40 observational cohorts of HIVpositive persons from 32 European countries within the EuroCoord Network of Excellence (www.eurocoord.net). In our analyses we included data from the 15 cohorts in eight European countries (Austria, France, Germany, Greece, Italy, Spain, Switzerland, and The Netherlands) that collect information on the educational level of HIV-positive patients.

Each cohort submitted data in a standardised format (the HIV Collaboration Data Exchange Protocol, http://www.hicdep.org) to coordinating centres at the Copenhagen HIV Program, Denmark, or the Institut de Santé Publique, d'Epidémiologie et de Développement (Bordeaux School of Public Health), Bordeaux, France. The Regional Coordinating Centres ensured that strict quality assurance guidelines were adhered to, checked the plausibility of data, and removed duplicate records. Data were pooled in the COHERE in EuroCoord 2014 merger, completed in September 2014. One of the cohorts included in the analysis did not submit to the 2014 merger (ANRS CO3Aquitaine); its submission from the previous year (2013) was used in the 2014 merger. Patients recruited between $1^{\text {st }}$ January, 1996 and $31^{\text {st }}$ December, 2013 were included if they were 18 years or older and belonged to cohorts that systematically collected data 
on educational level, initiated cART while antiretroviral-naïve, and had at least one CD4 count and one HIV-RNA measurement recorded in the six months before and the six months after starting cART. Patients were followed in each cohort according to routine clinical practice.

\section{Variables and definitions}

Data included age, sex, geographical origin, HIV-1 transmission category, use of cART (type of regime and start and stop dates), CD4 cell counts, and plasma HIV-RNA over time with dates of measurements, prevalent and incident AIDS defining conditions, dates of diagnoses, and vital status. cART was defined as a combination of either $\geq 3$ drugs from $\geq 2$ classes, or $\geq 3$ nucleoside reverse-transcriptase inhibitors, at least one of which was tenofovir or abacavir. Death and date of death were ascertained by reviewing charts or crosschecking with mortality registers. Further information on COHERE is available at www.cohere.org.

In 2012, EuroCoord investigators standardised data on educational level across cohorts. Maximum attained level of education was defined and classified according to the UNESCO/ISCED standard as no or incomplete primary (ISCED 0), primary (ISCED 1 and 2), secondary (ISCED 3 and 4), and tertiary (ISCED 5 and 6) based on data on education systems and reforms available from the European Encyclopaedia on National Education Systems (eacea.ec.europa.eu/education/eurydice/eurypedia_en.php).

\section{Outcomes}

Outcomes were time from cART initiation to i) death from any cause; ii) a new AIDSdefining event or death from any cause; iii) virological suppression, defined as the first 
of two consecutive HIV-RNA measurements $<400$ copies/mL, and an increase in CD4 cell count in the first 6 years of cART.

\section{Statistical analyses}

For mortality, clinical, and virological outcomes, we explored differences by educational level using Kaplan-Meier curves and log-rank tests. Hazard ratios (HRs) for the outcomes of interest were estimated using Cox proportional hazards models stratified by cohort.

Follow-up began at the start of cART and ended at the date the patient was last known to be alive, death, or the date of administrative censoring, whichever occurred first. We assumed that patients remained on therapy once cART was initiated, ignoring subsequent treatment changes or interruptions.

We used piecewise linear mixed models with a change in slope at 6 months after cART to compare trajectories of CD4 counts on the square root scale between educational groups over the first 6 years of cART. We determined the change point based on exploratory analyses using nonlinear models (17). To test for differences in rate of CD4 count recovery after cART, we included an interaction term between educational level and slope before and after the change point.

We chose, a priori, to adjust all models for the following potential confounding variables: sex; age at cART initiation; calendar period of cART initiation $(<2001,2001-$ 2004 and 2005-2008, 2009-2013); transmission category (men having sex with men [MSM], heterosexual, injecting drug users [IDU], other/unknown); country of origin/country of birth (Europe, non-European, unknown); pre-cART HIV-RNA on the $\log 10$ scale; pre-cART AIDS diagnosis; and initial class type of regime (non-nucleoside 
reverse transcriptase inhibitors [NNRTI], protease inhibitors PI], and others). We also adjusted models for clinical and virological response outcomes by pre-cART CD4 count category $\left(<200,200-349,350,499, \geq 500\right.$ cells $\left./ \mathrm{mm}^{3}\right)$. Moreover, we described differences by broad cohort geographical areas defined as Western and Northern Europe (Austria, France, Germany, the Netherlands, and Switzerland), and Southern Europe (Greece, Italy, and Spain). These analyses were descriptive and not adjusted for potential confounders. Finally, we described differences by educational level in the proportion of patients lost to follow-up. This was defined as the proportion of living individuals who had no medical encounter in the 18 months prior to the median last clinical encounter date for the corresponding cohort.

\section{Sensitivity analyses}

The main analyses excluded patients whose educational level was unknown. In sensitivity analyses we imputed missing data on education by multiple imputation using chained equations, assuming the data were missing at random (18). Twenty imputed data sets were generated, separately analyzed, and combined using Rubin's rule. We also used an extreme scenario analysis and assumed that data from patients with unknown educational level were not missing at random and corresponded to i) primary education, ii) secondary education, or iii) tertiary education. Since younger individuals may not yet have finished their education, we restricted analyses to patients aged $\geq 25$ years at cART initiation.

We used Stata statistical software, version 12 (StataCorp) for all analyses.

\section{Ethics}

All cohorts participating in COHERE adhere to local ethical standards, which extend to this study. 


\section{RESULTS}

A total of 35, 063 individuals met eligibility criteria. The main analyses were based on the 24, 069 individuals with data on educational level (69\%). The characteristics of patients with and without educational level data were similar (Appendix Table 1). Individuals with secondary and tertiary education were more likely to be male, to have been infected through male-to-male sex, and less likely to have been infected using injectable drugs, or to have recently initiated cART (Table 1). There were marked differences in the pre-cART CD4 counts, which were highest for those with higher levels of education. The prevalence of AIDS at the start of cART was also lower for those with higher education. The number and frequency of CD4 count and HIV-RNA measurements was similar across educational levels. The proportion of patients without completed primary education was considerably higher in Southern Europe than in other regions. Loss to follow-up was more common among patients with lower educational level.

\section{Mortality}

Over 132507 person-years of follow-up, 1081 individuals died. Cumulative mortality decreased as educational level increased ( $p<0.001$ log-rank test, Figure 1a). Differences in time to death persisted in the confounder-adjusted models; individuals without completed primary, primary, and secondary education had higher risks of death than those with tertiary education (Table 2a and Appendix table 2 (a) and 2 (b)). We found similar mortality gradients when we restricted analyses to those with CD4 >200 cells $/ \mathrm{mm}^{3}$ and no AIDS at cART initiation, and those with CD4>350 cells $/ \mathrm{mm}^{3}$ and no AIDS at cART initiation and age $\geq 25$ years (Appendix Table 3 ). We found no evidence of interaction by sex ( $p=0.582$ ) (Appendix Table 4). Our conclusions were robust to the sensitivity analyses for missing educational level, except for the very implausible 
scenario in which it was assumed that all individuals with missing educational level had tertiary education (data not shown).

\section{Incidence of AIDS or death}

Over 122765 person-years of follow-up, a new AIDS event or death occurred in 2598 individuals. Differences in the cumulative incidence of AIDS or death by educational level were more marked than for death alone $(\mathrm{p}<0.001$ log-rank test; Figure $1 \mathrm{~b}$, Table $2 b)$. We found no evidence of interaction by $\operatorname{sex}(p=0.314$, data not shown).

\section{Virological suppression}

At one year after initiating cART, 18468 individuals (77\%) had achieved virological suppression. Virological suppression was achieved by $85 \%$ of patients with primary education, $82 \%$ with secondary and $87 \%$ with tertiary education, and by $67 \%$ of patients with incomplete primary education $(\mathrm{p}<0.001$ log-rank test, Figure $1 \mathrm{c})$. The difference between groups became smaller over time, and was no longer evident from 10 years onwards. When we adjusted for potential confounders (particularly for transmission category), those with incomplete primary education and primary education had $20 \%$ and $7 \%$ lower risks, respectively, of achieving virological success than those with tertiary education (Table 2c).

\section{Immunological response}

The higher the educational level attained, the higher the CD4 count at cART initiation (Table 1) and at each point after cART initiation compared to patients with lower educational levels (Figure 2). However, there was no evidence that the rate of CD4 count recovery differed by educational level in the six months after cART initiation (Figure 2, Table 3). 


\section{DISCUSSION}

HIV-positive patients on combination antiretroviral therapy who had less education had higher mortality, higher rates of new AIDS events, and worse virological responses than patients under care who had more education. Patients with higher educational attainment also had higher CD4 cell counts at cART initiation and maintained higher CD4 cell counts over time compared to those less educated. We observed such health differentials for an eighteen-year period in eight European countries where access to health care and cART is universal, and gradients in mortality were similar for men and women. Men dominated in the participating cohorts, but women were over-represented in the lower educational strata. The present results build on our previous findings showing inequalities in HIV diagnosis and cART initiation by educational level in Western Europe (15). The striking differences in mortality and clinical responses to cART could not be explained entirely by delayed HIV diagnosis and late cART initiation, since differences largely remained after we restricted analyses to those initiating cART with CD4 >350 cells $/ \mathrm{mm}^{3}$ and without previous AIDS diagnoses.

The associations we found between educational level and clinical outcomes are probably mediated by material and psychosocial paths already conceptualized by various investigators (4-14,19-21), and by the Socioeconomic Inequalities and HIV Working Group of COHERE (15). Higher educational level is positively associated with choice of employment, higher salaries, and thus greater financial security, though the benefits of education on social outcomes persist after adjusting for income $(4,19$ 21). Educational achievement is also linked to health literacy and the ability to adhere to medication, as well as to healthier lifestyles (no smoking, good nutrition, and exercise; 
22-29). Psychosocial factors such as enhanced cognitive, social, and emotional skills and resources that help people cope with stressful life situations are also associated with educational accomplishment (27-29). Further, differentials by educational level are likely to be linked to causes that predate HIV infection and cART initiation. Indeed, excess mortality in disadvantaged populations has been widely reported in the EU, and better educated people live longer (1-2). By reducing HIV-related mortality, cART makes pre-existing mortality differentials by gender $(4,30-31)$, ethnicity, and migrant status more visible (4,32-33). A recent Danish study reported that elevated mortality observed in HIV-positive persons with low education was caused by non-AIDS defining lifestyle factors (smoking and alcohol use, 26). The increasing importance of non-AIDS morbidity and mortality in HIV-positive populations, secondary to smoking (25-28) and other risk-taking behaviours, will increase these socioeconomic gradients if no appropriate actions are taken. Finally, physicians may not prescribe optimum treatments to patients with lower educational attainment because inadvertently they may believe that they are too complex or difficult or to follow for less educated patients.

Poorer virological and immune response in less educated persons probably results from poorer adherence to cART, which relies heavily on psychosocial factors including social support and health literacy, which in turn are closely associated with educational attainment (34-36). Our results contribute to the body of evidence relating socioeconomic status and adherence to HIV medication, albeit through an indirect measure of treatment adherence since this is unavailable in the dataset. In a systematic review of data published up to 2006, Falagas et al. reported that about one-third of studies identified significant associations between educational level and adherence (36). More recently, Sobrino et al. have reported that less educated individuals have poorer 
short-term virological response to cART (9), and similar findings have been reported by Gueler et al. when socio-economic status is measured at the neighbourhood level (13). Immunological responses also have been reported to be less favourable in less educated persons $(9,14)$ due to incomplete HIV viral suppression. We did not find differential immunological recovery rates by educational level, though patients with more education maintained higher CD4 cell counts throughout follow-up. Monge et al. have reported higher resistance to any class of drugs in less educated HIV-positive individuals, and attributed it to on-going HIV replication as a result of poor adherence (37). Since the efficacy of life-long medication is grounded on adherence, interventions that target disadvantaged populations are key to controlling HIV. This could benefit from bringing in successful experiences from low-income countries including clinic-linked community-based adherence support interventions, which have proven successful in South-Africa (38)

A limitation of this study is that it was derived from the selection of patients recruited in cohorts who systematically collected information on educational status within the COHERE Collaboration. Additionally, as highlighted in previous work by the Socioeconomic Inequalities and HIV Working Group for COHERE, educational level is insufficient to fully capture socioeconomic status (15). Including other variables such as income and occupation may allow us to dissect these complex relationships $(4,19-20)$. Analyses of a number of variables that may mediate the effect of educational level on outcomes such as smoking, lifestyle, and health-seeking behaviours are also lacking. Indeed, understanding the causal relationship between educational level and these factors was beyond the scope of our work. Further, the fact that we did not detect significant gender differences may be a consequence of the relatively low number of 
women and their over-presentation in the lower educational strata. We hope our findings will encourage other researchers to collect information on socioeconomic status.. Our findings are robust to the various sensitivity analyses based on different assumptions about missing data patterns.

Our analyses are based on the largest cohort collaboration of HIV-positive patients within Europe, which allows systematic exploration of gender differences. We found no effect of gender on the associations between educational status, and mortality and new AIDS events. However, given the relatively lower number of women in HIV cohort studies eliciting relevant outcomes by sex is of great interest. In these eight European countries, the effect of educational level on HIV diagnosis and cART initiation persists after HIV-positive patients are in care and have started on potent and efficacious treatments. Educational disadvantage compromises cART effectiveness (15).

Our results have implications for policy intervention and program design at multiple levels. They support the argument for sustained educational efforts at the European level to improve active citizenship, social cohesion, and health impacting on the macrolevel determinants. They also reinforce the need for proximal down-stream interventions on clinical and preventive care among less educated HIV-positive patients once they are linked to care to address inequities. If these needs are met in accordance with the equity policy framework for Europe Health 2020 (38), the most vulnerable groups directly targeted by these interventions will benefit. As Scott-Samuel and Smith argue, though, it is unrealistic to expect inequalities to be substantially reduced without intensification of upstream policies challenging the wealth and power status quo of neoliberalism (40). 


\section{Acknowledgements}

The Socio-economic Inequalities and HIV Working Group for Collaboration of Observational HIV Epidemiological Research in Europe (COHERE) in

EuroCoord: Julia del Amo, Sara Lodi, Rosemary Dray-Spira, Linda Wittkop, Susana Monge, Dominique Braun, Janne Vehreschild, Ramon Teira, Colin Campbell, Antonella d'Arminio Monforte, Robert Zangerle, Jade Ghosen, Sofia Koukounti, François Dabis, Catherine Leport, Laurence Meyer, Monique Termote, Ole Kirk, Kholoud Porter, Bruno Spire, Genevieve Chêne, Matthias Egger.

Steering Committee_Contributing Cohorts: Ali Judd (AALPHI), Robert Zangerle (AHIVCOS), Giota Touloumi (AMACS), Josiane Warszawski (ANRS CO1 EPF/ANRS CO11 OBSERVATOIRE EPF), Laurence Meyer (ANRS CO2 SEROCO), François Dabis (ANRS CO3 AQUITAINE), Murielle Mary Krause (ANRS CO4 FHDH), Jade Ghosn (ANRS CO6 PRIMO), Catherine Leport (ANRS CO8 COPILOTE), Linda Wittkop (ANRS CO13 HEPAVIH), Peter Reiss (ATHENA), Ferdinand Wit (ATHENA), Maria Prins (CASCADE), Heiner Bucher (CASCADE), Diana Gibb (CHIPS), Gerd Fätkenheuer (Cologne-Bonn), Julia Del Amo (CoRIS), Niels Obel (Danish HIV Cohort), Claire Thorne (ECS), Amanda Mocroft (EuroSIDA), Ole Kirk (EuroSIDA), Christoph Stephan (Frankfurt), Santiago Pérez-Hoyos (GEMES-Haemo), Osamah Hamouda (German ClinSurv), Barbara Bartmeyer (German ClinSurv), Nikoloz Chkhartishvili (Georgian National HIV/AIDS), Antoni Noguera-Julian (CORISPE-cat), Andrea Antinori (ICC), Antonella d'Arminio Monforte (ICONA), Norbert Brockmeyer (KOMPNET), Luis Prieto (Madrid PMTCT Cohort), Pablo Rojo Conejo (CORISPESMadrid), Antoni Soriano-Arandes (NENEXP), Manuel Battegay (SHCS), Roger Kouyos (SHCS), Cristina Mussini (Modena Cohort), Pat Tookey (NSHPC), Jordi Casabona (PISCIS), Jose M. Miró (PISCIS), Antonella Castagna (San Raffaele), 
Deborah_Konopnick (St. Pierre Cohort), Tessa Goetghebuer (St Pierre Paediatric Cohort), Anders Sönnerborg (Swedish InfCare), Carlo Torti (The Italian Master Cohort), Caroline Sabin (UK CHIC), Ramon Teira (VACH), Myriam Garrido (VACH). David Haerry (European AIDS Treatment Group)

Executive Committee: Stéphane de Wit (Chair, St. Pierre University Hospital), Jose Mª Miró (PISCIS), Dominique Costagliola (FHDH), Antonella d'Arminio-Monforte (ICONA), Antonella Castagna (San Raffaele), Julia del Amo (CoRIS), Amanda Mocroft (EuroSida), Dorthe Raben (Head, Copenhagen Regional Coordinating Centre), Geneviève Chêne (Head, Bordeaux Regional Coordinating Centre). Paediatric Cohort Representatives: Ali Judd, Pablo Rojo Conejo.

Regional Coordinating Centres: Bordeaux RCC: Diana Barger, Christine Schwimmer, Monique Termote, Linda Wittkop; Copenhagen RCC: Maria Campbell, Casper M. Frederiksen, Nina Friis-Møller, Jesper Kjaer, Dorthe Raben, Rikke Salbøl Brandt.

Project Leads and Statisticians: Juan Berenguer, Julia Bohlius, Vincent Bouteloup, Heiner Bucher, Alessandro Cozzi-Lepri, François Dabis, Antonella d'Arminio Monforte, Mary-Anne Davies, Julia del Amo, Maria Dorrucci, David Dunn, Matthias Egger, Hansjakob Furrer, Marguerite Guiguet, Sophie Grabar, Ali Judd, Ole Kirk, Olivier Lambotte, Valériane Leroy, Sara Lodi, Sophie Matheron, Laurence Meyer, Jose Ma Miró, Amanda Mocroft, Susana Monge, Fumiyo Nakagawa, Roger Paredes, Andrew Phillips, Massimo Puoti, Michael Schomaker, Colette Smit, Jonathan Sterne, Rodolphe Thiebaut, Claire Thorne, Carlo Torti, , Marc van der Valk, Linda Wittkop, Natasha Wyss.

The authors gratefully acknowledge Christopher Ritter for language editing and commenting on the manuscript. 
Funding: The COHERE study group has received unrestricted funding from Agence Nationale de Recherches sur le SIDA et les Hépatites Virales (ANRS), France; HIV Monitoring Foundation, The Netherlands; and the Augustinus Foundation, Denmark. The research leading to these results has received funding from the European Union Seventh Framework Programme (FP7/2007-2013) under EuroCoord grant agreement $\mathrm{n}^{\circ}$ 260694. The group has also received project specific funding from The European Union Seventh Framework Programme (FP7/2007-2013) under Marie Curie grant agreement n8 n 274817 FOR Sara Lodi. A list of the funders of the participating cohorts can be found at www.COHERE.org. 


\section{References}

1. Mackenbach JP, Stirbu I, Roskam AJ, et al; European Union Working Group on Socioeconomic Inequalities in HealthSocioeconomic inequalities in health in 22 European countries. N Engl J Med 2008;358:2468-81.

2. Marmot M, Allen J, Bell R, Bloomer E, Goldblatt P, on behalf of the Consortium for the European Review of Social Determinants of Health and the Health Divide. WHO European review of social determinants of health and the health divide. The Lancet 2012; 380: 1011-1029.

3. Jemal A, Thun MJ, Ward EE, et al. Mortality from Leading Causes by Education and Race in the United States, 2001. Am J Prev Med 2008;34:1-8.

4. Dray-Spira R, Lert F. Social health inequalities during the course of chronic HIV disease in the era of highly active antiretroviral therapy. AIDS $2003 ; 17: 283-290$.

5.Protopopescu C, Carrieri MP, Le Moing V, et al. Socio-behavioural determinants of mortality in HIV-infected patients receiving combined antiretroviral treatment: results from the ANRS CO8 APROCO-COPILOTE cohort. In: 7th IAS conference on HIV pathogenesis, treatment and prevention Kuala Lumpur; 2013.

6. Dray-Spira R, Gueguen A, Persoz A, et al; PRIMO Cohort Study Group. Temporary employment, absence of stable partnership, and risk of hospitalization or death during the course of HIV infection. J Acquir Immune Defic Syndr 2005;40:190-7.

7.Jarrin I, Lumbreras B, Ferreros I, Perez-Hoyos S, Hurtado I, Hernandez-Aguado I. Effect of education on overall and cause-specific mortality in injecting drug 
users, according to HIV and introduction of HAART. Int J Epidemiol 2007; 36:187-194.

8.Monge S, Jarrín I, Pérez-Hoyos S, et al; GEMES. Educational level and HIV disease progression before and after the introduction of HAART: a cohort study in 989 HIV seroconverters in Spain. Sex Transm Infect 2011;87:571-576.

9. Sobrino-Vegas P, Rodriguez-Urrego J, Berenguer J, et al. Educational gradient in HIV diagnosis delay, mortality, antiretroviral treatment initiation and response in a country with universal health care. Antivir Ther 2012; 17(1):1-8.

10. Simard EP, Fransua M, Naishadham D, Jemal A. The Influence of Sex, Race/Ethnicity, and Educational Attainment on Human Immunodeficiency Virus Death. Rates Among Adults, 1993-2007 Arch Intern Med 2012;172:1591-1598

11. Legarth R, Omland LH, Kronborg G, et al. Educational attainment and risk of HIV infection, response to antiretroviral treatment, and mortality in HIVinfected patients. AIDS 2014;28:387-96.

12. Junghans C, Low N, Chan P, Witschi A, Vernazza P, Egger M. Uniform risk of clinical progression despite differences in utilization of highly active antiretroviral therapy: Swiss HIV Cohort Study. AIDS 1999;13:2547-54.

13. Gueler A, Schoeni-Affolter F, Moser A, et al; Swiss HIV Cohort Study, Swiss National Cohort. Neighbourhood socio-economic position, late presentation and outcomes in people living with HIV in Switzerland. AIDS 2015;29:231-8.

14. Collazos J, Asensi V, Carton JA, Ibarra S. The influence of the patients' educational levels on socioeconomic, clinical, immunological and virological endpoints. AIDS Care 2009; 21:511-519

15. Socio-economic Inequalities and HIV Writing Group for Collaboration of Observational HIV Epidemiological Research in Europe (COHERE) in 
EuroCoord. Delayed HIV diagnosis and initiation of antiretroviral therapy: inequalities by educational level, COHERE in EuroCoord. AIDS 2014;28:22972306.

16. Mustard CA, Etches J. Gender differences in socioeconomic inequality in mortality. J Epidemiol Community Health 2003;57:974-980.

17. Royston P, Sauerbrei W. Multivariable modeling with cubic regression splines: A principled approach. The Stata Journal 2007;7:45-70.

18. Sterne JA, White IR, Carlin JB, et al. Multiple imputation for missing data in epidemiological and clinical research: potential and pitfalls. $B M J$ 2009,338:b2393.

19. Galobardes B, Shaw M, Lawlor DA, Lynch JW, Davey SG. Indicators of socioeconomic position (part 1). J Epidemiol Community Health 2006; 60:7-12.

20. Galobardes B, Shaw M, Lawlor DA, Lynch JW, Davey SG. Indicators of socioeconomic position (part 2). J Epidemiol Community Health 2006; 60:95101.

21. Braveman PA, Cubbin C, Egerter S, et al. Socioeconomic status in health research: one size does not fit all. JAMA 2005; 294:2879-2888.

22. Dray-Spira R, Legeai C, Le Den M, et al; ANRS-COPANA Cohort Study Group. Burden of HIV disease and comorbidities on the chances of maintaining employment in the era of sustained combined antiretoviral therapies use. AIDS 2012;26:207-15.

23. Tron L, Lert F, Spire B, Dray-Spira R; ANRS-Vespa2 study group. Tobacco smoking in HIV-infected versus general population in France: heterogeneity across the various groups of people living with HIV. PLoS One 20142014 9;9(9):e107451. 
24. Huber M, Ledergerber B, Sauter R, et al; Swiss HIV Cohort Study Group. Outcome of smoking cessation counselling of HIV-positive persons by HIV care physicians. HIV Med 2012;13:387-97.

25. Helleberg M, May MT, Ingle SM, et al. Smoking and life expectancy among HIV-infected individuals on antiretroviral therapy in Europe and North America. AIDS 2015;29:221-9.

26. Helleberg M, Afzal S, Kronborg G, et al. Mortality attributable to smoking among HIV-1-infected individuals: a nationwide, population-based cohort study. Clin Infect Dis 2013;56:727-734.

27. Skalicka V, van LF, Bambra C, Krokstad S, Mackenbach J. Material, psychosocial, behavioural and biomedical factors in the explanation of relative socio-economic inequalities in mortality: evidence from the HUNT study. Int $J$ Epidemiol 2009; 38:1272-1284.

28. Shavers VL. Measurement of socioeconomic status in health disparities research. J Natl Med Assoc 2007;99:1013-1023.

29. Préau M, Protopopescu C, Raffi F, et al ANRS Co8 Aproco-Copilote Study Group. Satisfaction with care in HIV-infected patients treated with long-term follow-up antiretroviral therapy: the role of social vulnerability. AIDS Care 2012;24:434-43.

30. Jarrin I, Pantazis N, Gill MJ, et al; CASCADE Collaboration in EuroCoord. Uptake of combination antiretroviral therapy and HIV disease progression according to geographical origin in seroconverters in Europe, Canada, and Australia. Clin Infect Dis 2012;54:111-118. 
31. The Antiretroviral Therapy Cohort Collaboration (ART-CC). Sex differences in overall and cause-specific mortality among HIV-infected adults on antiretroviral therapy in Europe, Canada and the US. Antivir Ther 2015;20:21-8.

32. Jarrin I, Geskus R, Bhaskaran K, et al; CASCADE Collaboration. Gender differences in HIV progression to AIDS and death in industrialized countries: slower disease progression following HIV seroconversion in women. Am J Epidemiol 2008;168:532-40.

33. Antiretroviral Therapy Cohort Collaboration (ART-CC). Influence of geographical origin and ethnicity on mortality in patients on antiretroviral therapy in Canada, Europe, and the United States. Clin Infect Dis 2013;56:18009.

34. Carrieri MP, Leport C, Protopopescu C, et al. Factors associated with nonadherence to highly active antiretroviral therapy: a 5-year follow-up analysis with correction for the bias induced by missing data in the treatment maintenance phase. J Acquir Immune Defic Syndr 2006;41:477-85.

35. Bouhnik AD, Chesney M, Carrieri P, et al. Non-adherence among HIV-infected injecting drug users: the impact of social instability. J Acquir Immune Defic Syndr 2002,31 Suppl 3:S149-153.

36. Falagas ME, Zarkadoulia EA, Pliatsika PA, Panos G. Socioeconomic status (SES) as a determinant of adherence to treatment in HIV infected patients: a systematic review of the literature. Retrovirology 2008; 5:13.

37. Monge S, Guillot V, Alvarez M, et al. Analysis of transmitted drug resistance in Spain in the years 2007-2010 documents a decline in mutations to the nonnucleoside drug class. Clin Microbiol Infect 2012;18:E485-90. 
38. World Health Organization. Regional Office for Europe Health 2020: a

European policy framework supporting action across government and society for health and well-being. Malta, 10-13 September 2012.

39. Fatti G, Mothibi E, Shaikh N, Grimwood A. Improved long-term antiretroviral treatment outcomes amongst patients receiving community-based adherence support in South Africa. AIDS Care 2016 Jun 2:1-8

40. Scott-Samuel A, Smith KE. Fantasy paradigms of health inequalities: Utopian thinking? Social Theory \& Health 2015;13:418-436 
Appendix Table 1. Characteristics of patients with known and unknown educational level

\begin{tabular}{lrr}
\hline & Known & Unknown \\
\hline N (\%) & $24069(69 \%)$ & $10994(31 \%)$ \\
AIDS before cART & $16 \%$ & $15 \%$ \\
Median [IQR] age of cART, years & $37[31,44]$ & $37[30,44]$ \\
Median [IQR] year of cART & $2007[2002,2010]$ & $2006[2001,2010]$ \\
Median [IQR] CD4 count & $263[136,380]$ & $260[127,377]$ \\
Median [IQR] HIV RNA & $4.8[4.1,5.3]$ & $4.8[4.0,5.3]$ \\
Sex & $21 \%$ & $23 \%$ \\
Female & & \\
Male & $79 \%$ & $77 \%$ \\
Transmission category & & \\
Sex between men & $46 \%$ & $39 \%$ \\
Sex between men and women & $37 \%$ & $36 \%$ \\
Injecting drug use & $12 \%$ & $13 \%$ \\
Other/Unknown & $5 \%$ & $11 \%$ \\
Initial cART combination & & \\
NNRTI & $35 \%$ & $37 \%$ \\
PI & $49 \%$ & $46 \%$ \\
Other & $16 \%$ & $18 \%$ \\
Geographical origin & & \\
Europe & $68 \%$ & $11 \%$ \\
Other & $10 \%$ & $18 \%$ \\
Unknown & $22 \%$ & \\
& &
\end{tabular}

Copyright @ 2016 Wolters Kluwer Health, Inc. Unauthorized reproduction of this article is prohibited. 


\begin{tabular}{rr}
$12[6,23]$ & $11[5,22]$ \\
$4[3,5]$ & $4[3,5]$ \\
$4[2,8]$ & $4[2,8]$ \\
$11[5,21]$ & $11[5,22]$ \\
$4[3,5]$ & $4[3,5]$ \\
$4[2,7]$ & $4[2,8]$ \\
\hline
\end{tabular}




\section{Appendix Table 2.}

2 (a) Results from unadjusted and adjusted Cox model for time to death from any-cause after initiation of cAR

\begin{tabular}{|c|c|c|c|c|c|c|}
\hline \multirow[t]{2}{*}{ Characteristics at cART initiation } & \multicolumn{3}{|c|}{ Bivariate analyses } & \multicolumn{3}{|c|}{ Adjusted analyses } \\
\hline & Hazard ratio & $\begin{array}{l}95 \% \\
\text { confidence } \\
\text { interval }\end{array}$ & $P$ value & $\begin{array}{l}\text { Hazard } \\
\text { ratio }\end{array}$ & $\begin{array}{l}95 \% \\
\text { confidence } \\
\text { interval }\end{array}$ & $\mathrm{P}$ value \\
\hline \multicolumn{7}{|l|}{ Educational level } \\
\hline Incompleted basic & 2.54 & $(2.05,3.15)$ & & 1.93 & $(1.54,2.43)$ & \\
\hline Basic & 2.04 & $(1.62,2.56)$ & & 1.68 & $(1.32,2.12)$ & \\
\hline Secondary & 1.42 & $(1.15,1.75)$ & & 1.30 & $(1.05,1.60)$ & \\
\hline Tertiary & 1 & & $<0.001$ & 1 & & $<0.001$ \\
\hline Female & & $\mathrm{Xxx}$ & & 0.78 & $(0.66,0.92)$ & 0.003 \\
\hline Previous AIDS diagnosis & & & & 1.33 & $(1.16,1.54)$ & $<0.001$ \\
\hline \multicolumn{7}{|l|}{ Risk group } \\
\hline Sex between men & & & & 1 & & $<0.001$ \\
\hline Injecting drug use & & & & 2.93 & $(2.44,3.51)$ & \\
\hline Sex between men and women & & & & 1.14 & $(0.96,1.35)$ & \\
\hline Other & & & & 1.34 & $(0.78,2.31)$ & \\
\hline Unknown & & & & 1.49 & $(1.13,1.99)$ & \\
\hline Age (10 years) & & & & 1.74 & $(1.65,1.84)$ & $<0.001$ \\
\hline \multicolumn{7}{|l|}{ Calendar year } \\
\hline$<2001$ & & & & 1 & & $<0.001$ \\
\hline 2001-2004 & & & & 0.95 & $(0.80,1.13)$ & \\
\hline $2005-2008$ & & & & 0.76 & $(0.62,0.93)$ & \\
\hline 2009-2013 & & & & 0.60 & $(0.46,0.79)$ & \\
\hline Geographical Origin & & & & & & \\
\hline
\end{tabular}

Copyright $\odot 2016$ Wolters Kluwer Health, Inc. Unauthorized reproduction of this article is prohibited. 


\begin{tabular}{|c|c|c|c|}
\hline European & 1.06 & $(0.75,1.52)$ & 0.696 \\
\hline Non European & 1 & & \\
\hline Unknown & 0.71 & $(0.58,1.50)$ & \\
\hline \multicolumn{4}{|l|}{$\mathrm{CD} 4$ cell count, cells $/ \mathrm{mm}^{3}$} \\
\hline$<200$ & 1 & & 0.004 \\
\hline $200-349$ & 0.85 & $(0.73,0.99)$ & \\
\hline $350-499$ & 0.67 & $(0.54,0.84)$ & \\
\hline$\geq 500$ & 0.89 & $(0.71,1.12)$ & \\
\hline \multicolumn{4}{|l|}{ Initial cART combination } \\
\hline NNRTI based & 1.15 & $(0.98,1.34)$ & 0.001 \\
\hline PI based & 1 & & \\
\hline Other & 1.39 & $(1.16,1.67)$ & \\
\hline HIV-RNA (log10 scale) & 1.04 & $(0.97,1.10)$ & 0.273 \\
\hline
\end{tabular}

2 (b) Results from unadjusted and adjusted Cox model for time to a new AIDS event or death from any-cause after initiation of cART.

\begin{tabular}{|c|c|c|c|c|c|c|}
\hline Characteristics at cART initiation & $\begin{array}{l}\text { Bivariate anal } \\
\text { Hazard ratio }\end{array}$ & $\begin{array}{l}\text { yses } \\
95 \% \text { confidence interval }\end{array}$ & $\begin{array}{l}\mathrm{P} \\
\text { value }\end{array}$ & $\begin{array}{l}\text { Adjusted anal } \\
\text { Hazard ratio }\end{array}$ & $\begin{array}{l}\text { yses } \\
95 \% \text { confidence interval }\end{array}$ & $P$ value \\
\hline Educational level & & & & & & \\
\hline Incompleted basic & 2.19 & $(1.91,2.50)$ & & 1.60 & $(1.39,1.85)$ & \\
\hline Basic & 2.04 & $(1.62,2.56)$ & & 1.51 & $(1.30,1.75)$ & \\
\hline Secondary & 1.35 & $(1.19,1.54)$ & & 1.21 & $(1.06,1.38)$ & \\
\hline Tertiary & 1 & & $<0.001$ & 1 & & $<0.001$ \\
\hline Female & & & & 0.9 & $(0.81,1.00)$ & 0.052 \\
\hline Previous AIDS diagnosis & & & & 1.33 & $(1.22,1.46)$ & $<0.001$ \\
\hline Risk group & & & & & & \\
\hline
\end{tabular}




\begin{tabular}{|c|c|c|c|}
\hline Sex between men & 1 & & $<0.001$ \\
\hline Injecting drug use & 1.84 & $(1.63,2.07)$ & \\
\hline Sex between men and women & 1.12 & $(1.01,1.25)$ & \\
\hline Other & 1.20 & $(0.83,1.75)$ & \\
\hline Unknown & 1.29 & $(1.06,1.56)$ & \\
\hline Age (10 years) & 1.74 & $(1.65,1.84)$ & $<0.001$ \\
\hline \multicolumn{4}{|l|}{ Calendar year } \\
\hline$<2001$ & 1 & & $<0.001$ \\
\hline $2001-2004$ & 0.85 & $(0.76,0.95)$ & \\
\hline $2005-2008$ & 0.65 & $(0.58,0.74)$ & \\
\hline 2009-2013 & 0.57 & $(0.49,0.66)$ & \\
\hline \multicolumn{4}{|l|}{ Geographical Origin } \\
\hline European & 0.89 & $(0.74,1.06)$ & 0.058 \\
\hline Non European & 1 & & \\
\hline Unknown & 0.72 & $(0.55,0.95)$ & \\
\hline \multicolumn{4}{|l|}{ CD4 cell count, cells/mm3 } \\
\hline$<200$ & 1 & & $<0.001$ \\
\hline $200-349$ & 0.58 & $(0.53,0.65)$ & \\
\hline $350-499$ & 0.47 & $(0.41,0.55)$ & \\
\hline$\geq 500$ & 0.52 & $(0.44,0.61)$ & \\
\hline \multicolumn{4}{|l|}{ Initial cART combination } \\
\hline NNRTI based & 1.12 & $(1.02,1.24)$ & $<0.001$ \\
\hline PI based & 1 & & \\
\hline Other & 1.36 & $(1.21,1.52)$ & \\
\hline HIV-RNA (log10 scale) & 1.14 & $(1.09,1.19)$ & 0.273 \\
\hline
\end{tabular}

Copyright $\odot 2016$ Wolters Kluwer Health, Inc. Unauthorized reproduction of this article is prohibited. 
Appendix Table 3. Adjusted hazard ratios for sensitivity analyses restricting to patients with i) CD4>200 cells/mm3 and no AIDS at cART initiation, ii) with CD4 $>350$ cells $/ \mathrm{mm} 3$ and no AIDS at cART initiation and iii) age $\geq 25$ years

\begin{tabular}{lrrr}
\hline Educational level & CD4>200 and no AIDS (N & CD4>350 and no AIDS (N 7028) & Age $\geq 25(\mathrm{~N}=22922)$ \\
\hline Incompleted basic & $2.38(1.63,3.50)$ & $1.79(1.00,3.17)$ & $1.94(1.54,2.44)$ \\
Basic & $2.04(1.39,3.00)$ & $2.14(1.23,3.71)$ & $1.67(1.31,2.12)$ \\
Secondary & $1.70(1.21,2.35)$ & $1.36(0.83,2.22)$ & $1.29(1.05,1.60)$ \\
Tertiary & 1 & 1 & 1 \\
& $\mathrm{p}<0.001$ & $\mathrm{p} 0.039$ & $\mathrm{p}<0.001$ \\
\hline
\end{tabular}

*Models adjusted for sex, risk group, previous AIDS diagnosis, calendar period, initial cART combination, geographical origin, CD4 count, age and HIV-RNA at cART initiation 
Appendix Table 4. Assessing the role of gender as an effect modifier. Unadjusted and adjusted* time ratios of mortality for males and females and results from the likelihood ratio test to test the interaction by gender.

\begin{tabular}{lrrrr}
\hline & \multicolumn{2}{c}{ Unadjusted } & \multicolumn{2}{c}{ Adjusted } \\
\cline { 2 - 5 } Educational level & Male $(\mathrm{N}=18906)$ & Female $(\mathrm{N}=5163)$ & Male $(\mathrm{N}=18906)$ & Female $(\mathrm{N}=5163)$ \\
\hline Incompleted basic & $2.87(2.27,3.62)$ & $3.04(1.55,5.94)$ & $1.89(1.47,2.43)$ & $2.84(1.43,5.66)$ \\
Basic & $2.25(1.75,2.89)$ & $2.36(1.18,4.70)$ & $1.71(1.32,2.21)$ & $2.17(1.07,4.38)$ \\
Secondary & $1.40(1.12,1.75)$ & $2.02(1.03,3.96)$ & $1.27(1.01,1.58)$ & $1.91(0.97,3.78)$ \\
Tertiary & 1 & 1 & 1 & 1 \\
Likelihood ratio test & \multicolumn{2}{c}{0.352} & \multicolumn{2}{c}{ p 0.566 } \\
for interaction & \multicolumn{2}{c}{$\mathrm{p} 0.352$} & \multicolumn{2}{c}{1} \\
\hline
\end{tabular}

*Models adjusted for risk group, previous AIDS diagnosis, calendar period, initial cART combination, geographical origin, CD4 count, age and HIV-RNA at cART initiation and stratified by cohort. 
Figure 1. Cumulative incidence of mortality (a), AIDS or mortality (b), and virological success (c) after initiation of combined antiretroviral therapy (CART) by educational level.

a.

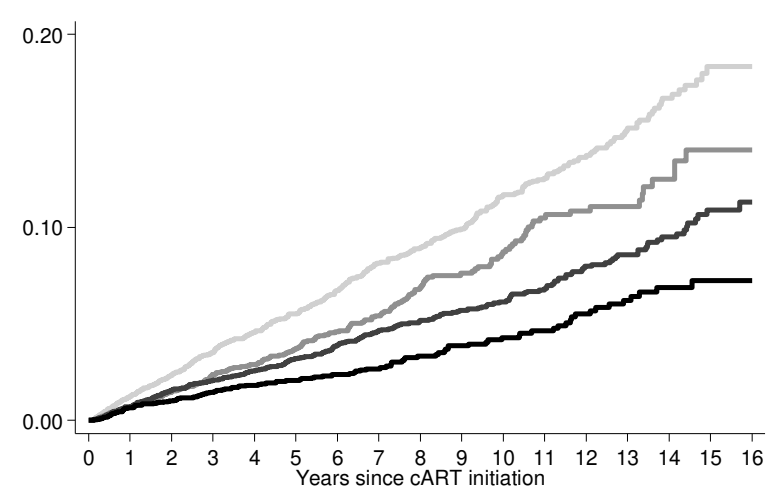

b.

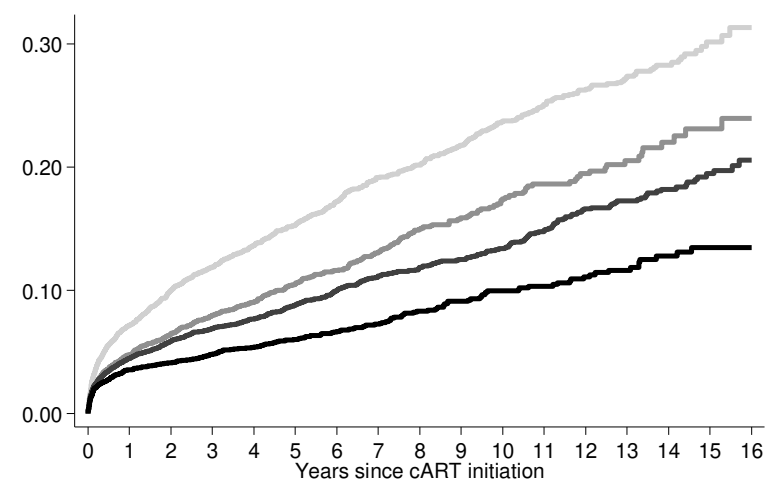

C.

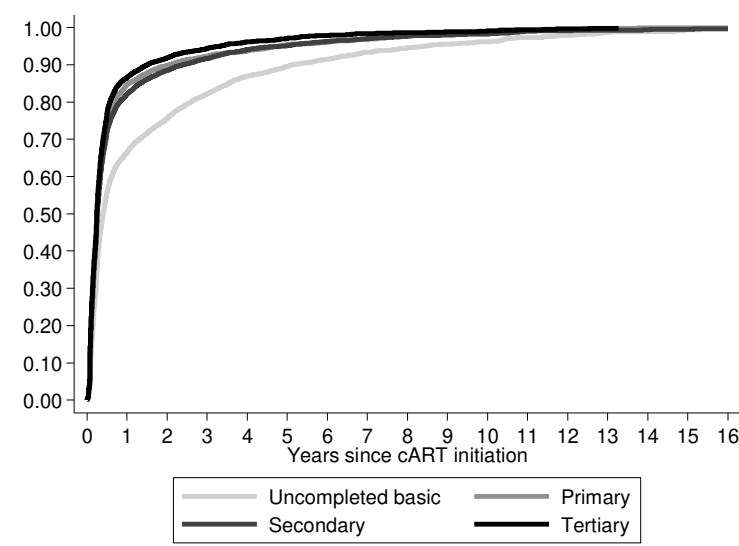


Figure 2. Estimated of in CD4 count after CART initation from a piecewise linear mixed model. Baseline individual: no AIDS, male, MSM, CART initiation <2001, European origin, NNRTI-based initial CART combination, age 37 years and viral load of 5.4 log copies/mL.

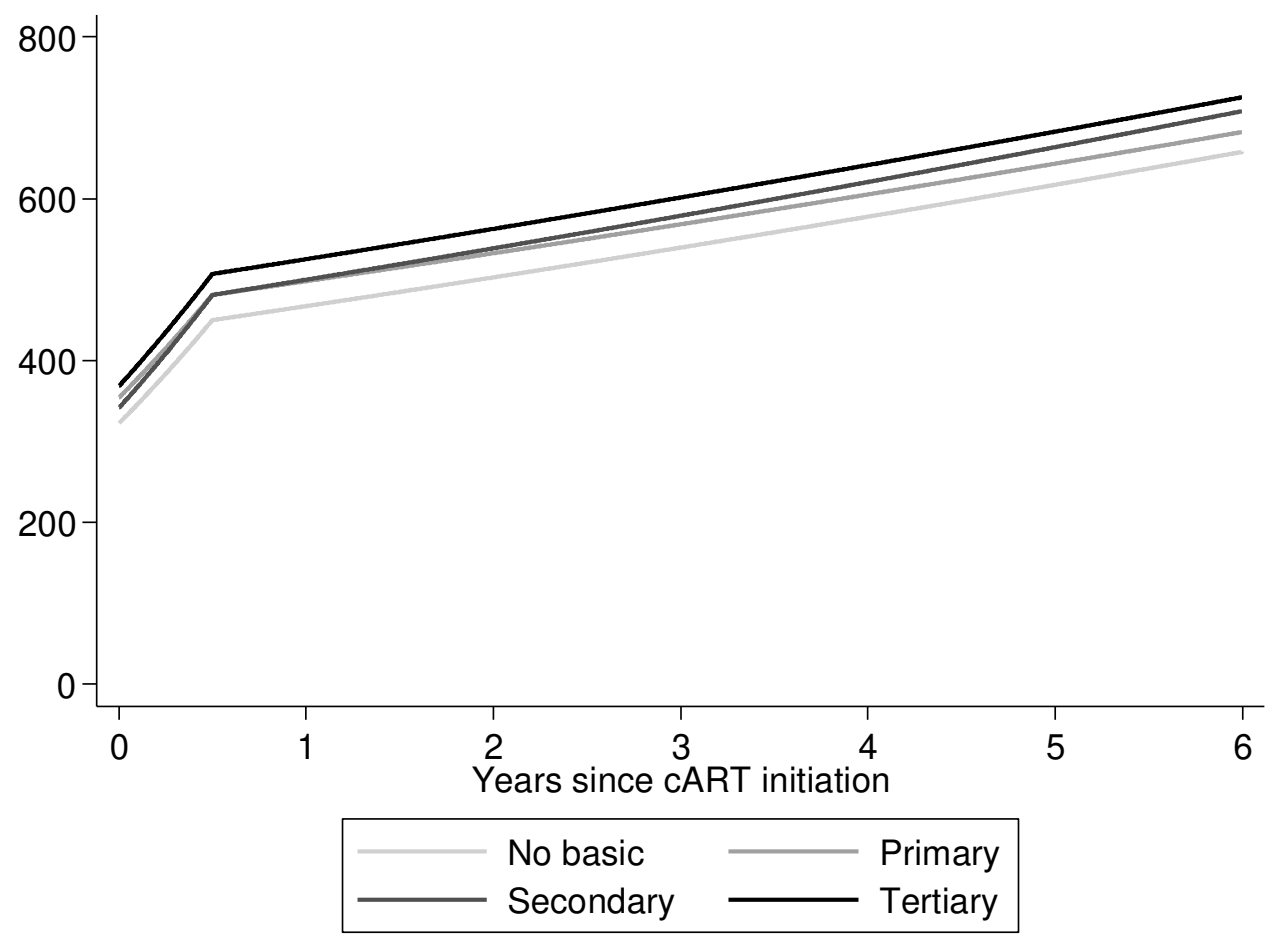


Table 1 Patient characteristics at cART initiation, overall, and by educational level

\begin{tabular}{|c|c|c|c|c|c|}
\hline & Incompleted primary & Primary & Secondary & Tertiary & Overall \\
\hline $\mathrm{N}(\%)$ & $5719(9 \%)$ & $4999(32 \%)$ & $7945(44 \%)$ & $5406(15 \%)$ & $24069(100 \%)$ \\
\hline \multicolumn{6}{|l|}{ Sex } \\
\hline Female & $1851(32 \%)$ & $1307(26 \%)$ & $1462(18 \%)$ & $543(10 \%)$ & $5163(21 \%)$ \\
\hline \multicolumn{6}{|l|}{ Transmission category } \\
\hline Sex between men & $1057(18 \%)$ & $1800(36 \%)$ & $4275(54 \%)$ & $3919(73 \%)$ & $11051(46 \%)$ \\
\hline Sex between men and women & $2938(51 \%)$ & $2242(45 \%)$ & $2674(37 \%)$ & $1123(21 \%)$ & $8977(37 \%)$ \\
\hline Other/Unknown & $311(5 \%)$ & $228(5 \%)$ & $349(4 \%)$ & $246(5 \%)$ & $1134(5 \%)$ \\
\hline Median [IQR] age of cART, years & $37[31,45]$ & $37[31,45]$ & $37[31,44]$ & $37[31,43]$ & $37[31,44]$ \\
\hline Median [IQR] year of cART & $2005[2001,2009]$ & $\begin{array}{r}2007 \\
{[2003,2010]}\end{array}$ & $\begin{array}{r}2007 \\
{[2003,2010]}\end{array}$ & $\begin{array}{r}2008 \\
{[2004,2011]}\end{array}$ & $\begin{array}{r}2007 \\
{[2002,2010]}\end{array}$ \\
\hline \multicolumn{6}{|l|}{ Geographical origin } \\
\hline Europe & $4466(78 \%)$ & $3384(68 \%)$ & $5132(65 \%)$ & $3419(63 \%)$ & $16401(68 \%)$ \\
\hline Number of CD4 count per patient & $13[6,24]$ & $12[6,22]$ & $12[6,23]$ & $11[5,21]$ & $12[6,22]$ \\
\hline $\begin{array}{l}\text { Mean CD4 count interval per patient } \\
\text { (months) }\end{array}$ & $4[3,6]$ & $4[3,5]$ & $4[3,5]$ & $4(3,5)$ & $4[3,5]$ \\
\hline Median [IQR] HIV RNA & $4.9[4.2,5,4]$ & $4.8[4.1,5.3]$ & $4.8[4.2,5.3]$ & $4.8[4.2,5.3]$ & $4.8[4.2,5.3]$ \\
\hline Number of HIV RNA & $12[6,23]$ & $11[6,20]$ & $11[5,21]$ & $10[5,19]$ & $11[6,21]$ \\
\hline $\begin{array}{l}\text { Mean per patient HIV RNA interval } \\
\text { (months) }\end{array}$ & $4[3,6]$ & $4[3,5]$ & $4[3,57]$ & $4[3,5]$ & $4[3,5]$ \\
\hline
\end{tabular}


Initial cART combination NNRTI

PI

Other

Cohort geographical area

Greece, Italy, Spain

Austria, Germany, Netherlands,

Switzerland

Median follow-up, years

Proportion lost to follow-up

\begin{tabular}{rrrr|r}
$2096(37 \%)$ & $1853(37 \%)$ & $2744(35 \%)$ & $1735(32 \%)$ & $8428(35 \%)$ \\
$2768(48 \%)$ & $2218(44 \%)$ & $3960(50 \%)$ & $2763(51 \%)$ & $11709(49 \%)$ \\
$855(15 \%)$ & $928(19 \%)$ & $1241(16 \%)$ & $908(17 \%)$ & $3932(16 \%)$ \\
$4748(83 \%)$ & $2855(57 \%)$ & $5574(70 \%)$ & $3373(62 \%)$ & $16550(69 \%)$ \\
$971(17 \%)$ & $2144(43 \%)$ & $2371(30 \%)$ & $2033(38 \%)$ & $7519(31 \%)$ \\
5.2 & 4.1 & 4.4 & & \\
$1486(28 \%)$ & $1006(20 \%)$ & $1427(18 \%)$ & $893(17 \%)$ & $4812(21 \%)$ \\
\hline
\end{tabular}

Copyright $\odot 2016$ Wolters Kluwer Health, Inc. Unauthorized reproduction of this article is prohibited. 
Table 2. Differences in mortality, new AIDS event/death, virological suppression from cART initiation according to educational level

\begin{tabular}{|c|c|c|c|c|c|c|}
\hline Educational level & a) & Mortality & b) & New AIDS event or mortality & c) & Virological success \\
\hline Incompleted primary & & $1.93(1.54,2.43)$ & & $1.60(1.39,1.85)$ & & $0.80(0.76,0.84)$ \\
\hline Primary & & $1.68(1.32,2.12)$ & & $1.51(1.30,1.75)$ & & $0.93(0.89,0.97)$ \\
\hline Secondary & & $1.30(1.05,1.60)$ & & $1.21(1.06,1.38)$ & & $0.97(0.94,1.01)$ \\
\hline Tertiary & & 1 & & 1 & & 1 \\
\hline & & $\mathrm{p}<0.001$ & & $\mathrm{p}<0.001$ & & $\mathrm{p}<0.001$ \\
\hline
\end{tabular}

*Cox models adjusted for sex, risk group, previous AIDS diagnosis, calendar period, initial cART combination, geographical origin, CD4 count, age and HIV-RNA at cART initiation and stratified by cohort. 
Table 3. Estimates of change in square root CD4 count after initiation of combined antiretroviral therapy (cART) from a piecewise linear mixed model.

\begin{tabular}{lrrrr}
\hline & Estimate & & $(95 \% \mathrm{CI})$ & $\mathrm{P}$ \\
\hline CD4 count at time 0 for baseline* patient with tertiary education & 21.96 & $(21.49$, & $22.42)$ & $<0.001$ \\
Incompleted primary & -1.24 & $(-1.50$, & $-0.97)$ & \\
Primary & -0.38 & $(-0.63$, & $-0.12)$ & \\
Secondary & -0.71 & $(-0.94$, & $-0.48)$ & \\
Tertiary & ref & & & $<0.001$ \\
Annual rate of increase in the first 6 months for baseline patient with tertiary education & 6.67 & $(6.37$, & $6.96)$ & $<0.001$ \\
Incompleted primary & -0.14 & $(-0.57$, & $0.30)$ & \\
Primary & -0.41 & $(-0.83$, & $0.02)$ & \\
Secondary & 0.25 & $(-0.13$, & $0.64)$ & \\
Tertiary & ref & & & 0.111 \\
Annual rate of increase after 6 months for tertiary education & 0.80 & $(0.76$, & $0.85)$ & $<0.001$ \\
Incompleted primary & 0.00 & $(-0.05$, & $0.06)$ & \\
Primary & -0.04 & $(-0.10$, & $0.02)$ & \\
Secondary & 0.05 & $(-0.01$, & $0.10)$ & \\
Tertiary & ref & & & 0.115 \\
Pre-cART AIDS & -3.62 & $(-3.79$, & $-3.44)$ & $<0.001$ \\
Sex & & & & \\
Male & ref & & & \\
Female & 0.39 & $(0.21$, & $0.57)$ & $<0.001$ \\
Mode of exposure & & & & $<0.001$ \\
Sex between men & ref & &
\end{tabular}

Copyright $\odot 2016$ Wolters Kluwer Health, Inc. Unauthorized reproduction of this article is prohibited. 
Other

Unknown

Age at cART, 10 year

Year at cART initiation

$<2001$

2001-2004

2005-2008

2009-2013

Geographical origin

European

Non -European

Other

Initial cART combination

NNRTI

PI

Other

Viral load (log10 scale)

\begin{tabular}{rrrr}
-1.16 & $(-1.82$, & $-0.50)$ & \\
-1.29 & $(-1.63$, & $-0.96)$ & \\
-0.56 & $(-0.62$, & $-0.50)$ & $<0.001$ \\
& & & \\
-1.58 & $(-1.79$, & $-1.38)$ & $<0.001$ \\
-2.16 & $(-2.36$, & $-1.97)$ & \\
-1.58 & $(-1.74$, & $-1.42)$ & \\
ref & & & \\
& & & \\
ref & & & $<0.001$ \\
-1.03 & $(-1.25$, & $-0.81)$ & \\
-0.63 & $(-0.79$, & $-0.47)$ & \\
& & & \\
ref & & & 0.024 \\
-0.21 & $(-0.36$, & $-0.06)$ & \\
-0.05 & $(-0.23$, & $0.13)$ & \\
-0.32 & $(-0.38$, & $-0.26)$ & $<0.001$ \\
\hline
\end{tabular}

